\title{
Organising National Olympiads in Informatics: a Review of Selection Processes, Trainings and Promotion Activities
}

\author{
Sébastien COMBÉFIS ${ }^{1,2}$, Alexis PAQUES 2 \\ ${ }^{1}$ Electronics and IT Unit, École Centrale des Arts et Métiers (ECAM) \\ Promenade de l'Alma 50, 1200 Woluwé-Saint-Lambert, Belgium \\ ${ }^{2}$ Computer Science and IT in Education ASBL, Belgium \\ e-mail:s.combefis@ecam.be, alexis.paques@csited.be
}

\begin{abstract}
For a country to be allowed to send a national delegation to the International Olympiad in Informatics (IOI), it must organise a national competition to select the national delegation. In addition to the competition, trainings can also be proposed to the selected contestants to train them specifically for the IOI. How to organise the national contests is at the discretion of countries, so far as fairness is ensured among all the potential candidates. This paper reviews common structural elements and activities organised by several countries, for the advertisement of the national contest, the steps of the selection process and the proposed trainings. Specific activities added by countries according to cultural aspects or other country-specific characteristics are highlighted with the reasons motivating the integration of those activities. Based on the review, this paper summarises the key activities that could be organised by any country, with explanations about what they bring to the national contestants and motivation for their organisation.
\end{abstract}

Keywords: national Olympiad in informatics, national IOI delegation selection process, trainings activities and camps.

\section{Introduction}

When considering competitions as a tool to support and strengthen education, opinions differ, even though most people agree that education and competitions are closely related. It is natural for children to compete and competitions are also important in adult life; competitions should therefore be part of education (Verhoeff, 1997). In particular, all the activities revolving around competitions, and all the material produced, if used properly, enhance teaching and learning of concepts, such as in informatics, for example (Combéfis and Wautelet, 2014).

The first international Olympiad in the field of informatics was organised in 1988 by the Association for Technical Culture of Slovenia (Zrimec, 1989). The International 
Olympiad in Informatics (IOI) is a competitive programming competition that supports the education of informatics, recognised and supported by UNESCO, launched in Bulgaria, in 1989 (Manev et al., 2007). In particular, this competition is a good force for promoting programming and algorithm design fields of computer science. It is also an opportunity for countries all over the world to promote and push informatics in the education of young pupils, through the organisation of National Olympiad in Informatics (NOI). Many other regular international Olympiad in informatics are organised such as the Balkan Olympiad in Informatics (BOI) launched in 1993 at the initiative of Romania, the Central-European Olympiad in Informatics (CEOI) first organised in 1994 and again founded by Romania gathers nine countries, and the Baltic Olympiad in Informatics (BOI) created in 1995, which started with only three participating countries and now encompasses about 60 participants from nine countries.

This paper reviews how NOIs are organised in various countries, and how they are used to foster the spread of informatics in schools. It also puts forward good practices and highlights difficulties encountered by some countries.

Section 2 summarises the goals of NOIs, the main organisational and promotional difficulties and the structure of institutions being in charge of organising NOIs.

Section 3 reviews the selection process and, more precisely, it examines how the candidates are graded and selected to be part of the national IOI delegation.

Section 4 covers the trainings proposed to the contestants and the national delegation, before the IOI. It also sums up additional activities organised in countries to promote informatics and attract pupils to take part in the NOI.

Finally, the last section concludes the paper with some open questions and suggestions to improve the overall participation to the various existing national/regional/international Olympiads in Informatics and to better disseminate informatics in schools.

\section{National Olympiad in Informatics}

Each country that wants to send a national delegation to the IOI must organise a national contest to make the selection of the national IOI delegation. This section summarises the goals and the organisation of the National Olympiads in Informatics (NOIs) as well as how they are promoted in the country.

\subsection{Goals of the National Olympiads in Informatics}

According to the institutions organising the NOI in various countries, informatics Olympiads play an important role in the introduction of informatics, in particular of programming, in secondary schools. In some countries, the NOI is the biggest ICT related competition, such as in Mongolia, for example (Choijoovanchig et al., 2007).

The main goals of the NOI are similar for most countries, that is, to encourage the teaching of programming in schools. More specifically, the main goals can be summarised as follows: 
- The NOI can stimulate the interest for informatics and programming among secondary school pupils and teachers. In China, for example, it has been demonstrated that the NOI plays a role in the promotion and popularisation of information technology in secondary schools (Wang et al., 2007).

- Talented teachers and pupils are brought together thanks to the NOI, which fosters the promotion of the contest in schools and collaboration between several institutions (schools, universities, associations and ministries). It is therefore a way to identify those talented pupils, and encourage them to pursue further opportunities in the profession and enrol in computer science related programs at universities.

- All the educational material produced for NOI, mainly tasks with solutions, syllabuses, training material or handbooks, can be used to motivate teachers to start activities related to informatics in their schools.

- Finally, the most obvious goal is simply to find talented pupils that will be part of the national IOI delegation and will succeed in bringing back medals from the IOI.

\subsection{Promotion of National Olympiads in Informatics}

Organising a nationwide contest and promoting it among teachers is not an easy task, as highlighted in (Pohl, 2007). A direct consequence is a low participation rate to the NOI. Several reasons have been highlighted:

- The responsibility for schools is not always at the level of the nation, which makes NOI difficult to promote, such as in Germany or in Belgium, for example (Combéfis and Leroy, 2011; Mukund, 2013; Pohl, 2007).

- There can be a lack of a centralised contest organisation, which makes it difficult for teachers in schools to decide which contest to recommend to their pupils. Indeed, the market of contests is large since NOI is not the only prestigious scientific contest with a corresponding international Olympiad, and NOI is not the only informatics related contest in most countries.

- Informatics is not a mandatory subject in schools - it is taught at most as an elective subject - which means that pupils do not know how to program nor have any knowledge in algorithm design and consequently do not participate in programming contests. A direct side effect is that there are only few professional informatics teachers, making the level of informatics education in schools very low.

- Financial issues can also arise in some countries. For example, Finland lost its main sponsor, which vanished into its possibility to organise a three-step NOI (Koivisto, 2013). The country had to consider using online competitions instead of in school contests - this dramatically reduced the number of contestants.

A direct consequence of those issues is that some potential talented candidates may miss the opportunity to participate in the national Olympiad and therefore be part of the national IOI delegation, just because they was not aware of the informatics Olympiad. 
They may have discovered a passion for programming and may have shown good programming skills, but are instead just pursuing a normal life, without informatics...

In addition to these difficulties related to the organisation of the NOI, it is not always easy for some countries to participate and send a delegation to the IOI. Several reasons have been put forward:

- Pupils from some countries have insufficient English skills, which make it difficult for them to understand the tasks and to use online resources such as online Olympiads.

- The financial situation can also prevent a country from participating at the IOI every year: the low annual budget can make it impossible to cover all annual expenses. For example, Japan was not able to participate to all the IOIs (Tani and Moriya, 2008).

- It is not always possible for people from developing countries to get a visa to enter some developed countries, preventing them to participate to some IOIs. For example, Mongolia and Bangladesh were not able to attend several IOIs (Choijoovanchig et al., 2007; Kaykobad, 2013).

It is not easy to address these issues, as they depend mainly on political decisions and on the economic situation of countries. Nevertheless, countries have taken some actions. Some countries are saving their money and decided to only participate to some IOIs. For the visa issue, some countries are participating online and then compare themselves to others thanks to the public rankings.

Promoting the NOI is also difficult. Contacts have to be found within schools, and human resources have to be allocated to go to schools and explain to the teachers what is the informatics Olympiad about. Some countries have developed interesting promotional materials to spread the word about informatics:

- Bangladesh convinced a newspaper to allocate space to publish math puzzles and problems for their young readers (Kaykobad, 2013). This action was a large success as thousands of pupils stormed into the office of the newspaper with their solutions. Doing the same with small algorithmic problems could be a good promotion vector.

- Georgia started developing an online Olympiad thanks to the Olympiad alumni, now working as professional programmers at various companies who gathered money from several sponsors (Mandaria, 2013). This platform allows contestants to compete more frequently and is a useful tool for identifying talented pupils.

- Development of books with materials about informatics, solved tasks with detailed solutions and explanations, and theoretical concepts related to programming, time complexity and algorithm design, for example (Mandaria, 2013).

Motivating pupils to participate at NOIs can be done in several ways. For example, Thailand is offering scholarships for contestants selected for the national IOI delegation (Malaivongs, 2013). Most countries offer medals and/or prizes to contestants that perform well on several stages of the NOI. 


\subsection{Organisation of National Olympiads in Informatics}

Depending on the country, the NOI is either organised by a single institution or cooperatively by several institutions. In most countries, a national association has been created to promote informatics, such as the Croatian Computer Science Association, the Computer Society of Macedonia, the Italian Association for Informatics, the China Computer Federation or the Institute for the Promotion of Teaching Science and Technology in Thailand, for example. A committee is then put in place, with collaborators from the Ministry of Education, universities, high schools and ICT industries, to organise the national Olympiad.

Several aspects have to be taken into account when organising and managing a NOI. The separation of roles is more or less clear, depending on the country. For example, the organisation of the Italian Olympiad in Informatics is split among three groups (Casadei et al., 2007), which occurs in many countries:

- The scientific group is responsible for the definition of the selection process and trainings, the composition of the national team for the IOI delegation.

- The administrative group takes care of the contacts with the schools and handles the logistics of the selection process.

- The technical group is in charge of the creation of tasks, the evaluation of the programs written by the contestants and has to organise teaching and trainings for the winners of the national Olympiad.

Another potential difficulty for some countries is related to the schedule. The IOI usually takes place during July or August, which is not holiday in some countries, such as Thailand, for example (Malaivongs, 2011). Many countries must adapt their schedules to the national IOI delegation process.

\section{Selection Process}

The selection process for the national IOI delegation varies by countries, though they share several key points. In most countries, the final of the national Olympiad is simply a small-scale copy of the IOI, which is preceded by multiple selection steps. Some countries have added pen-and-paper rounds in addition to more traditional computer rounds, such as in Belgium (Combéfis and Leroy, 2011).

The format of the NOI is chosen according to the skills that the country organisers want their contestants to develop. For most countries, the NOI is focused on algorithm design and practical programming skills; the contest is therefore centred on solving tasks on a computer. But some countries, such as Slovakia, are focusing on the thinking process (problem solving process), arguing that it is what they will need in their future lives if they chose a career in computer science; the contest having therefore more paper rounds supervised by human judges (Forišek, 2007; Forišek, 2013). 
One important point of interest for the selection process for many countries, such as Latvia and China, for example, is the establishment of strict rules that define how the national IOI delegation is selected (Opmanis, 2013; Wang et al., 2010).

\subsection{Organised Contests and Levels}

The selection process for the national IOI delegation expands through one or two years, depending on the country. Limiting the duration of the selection process to one year makes it easier to have candidates participating more than once to the IOI. Extending the selection process for two years allows the candidates to be more trained, which increases the chance to reach first positions in the ranking during the IOI. In most countries, the national Olympiad is split into several stages starting with local contests, followed by the provinces/regional contests, and finally leading to one nationwide final.

Here are the most common stages of national Olympiads:

- School competitions are organised in schools by teachers, and are generally a compulsory step, but without a qualifying meaning, such as in Latvia (Opmanis, 2013). Such a stage is very useful for promotional purposes, and is rather easy to organise, as the teachers handle it locally. It allows pupils to test their willingness to participate in the national Olympiad. Practically, this can either be a penand-paper contest, which is easier for the teacher, or a computer-based contest, in which case the best solution is to propose an online platform to support the contest.

- Regional competitions are organised by regions/provinces/districts, and have a qualifying status. The main goal for contestants is therefore to qualify for the next level of competitions. The qualified contestants are generally selected based on one unique nationwide ranking. However, in some countries, at least one contestant by region is selected, for promotion and equity purposes. Such a stage is generally organised into a set of schools where enthusiastic teachers supervise the contestants that participate in the contest through an online platform.

- Country competition, often referred to as final, is organised as an on-site competition whose location can change every year, generally hosted by a local university or university college.

- Selection competition is an additional level of competition that some countries organise to select contestants that will be part of the national delegation for regional contests such as the BOI or CEOI, and for the national IOI delegation. That stage is usually very similar to the IOI, namely a two-day on-site competition based on programming tasks to solve with a computer.

Some countries do not work in such a structure. For example, Thailand only has several nationwide contests interleaved with training camps, which results in the selection of about 100 contestants for the NOI (Malaivongs, 2013). Another quite spread habit is to organise some of the selection steps as online contests as it is the case in Japan and Germany, for example (Pohl, 2007; Tani and Moriya, 2008). Finally, some countries, 
such as India, are explicitly organising two separate contests in the first stage, one penand-paper style to test algorithmic insight and one on computers to test programming skills (Mukund, 2013).

Table 1 shows a summary of an average participation rate, in term of the number of contestants, for the different stages of the NOI in several countries. It reveals that some countries are trying to have widespread local competitions, to reach a lot of pupils (mainly for promotion) and to allow the highest number of them to enter the competition, whereas other countries are more focused on the selection for the IOI, directly starting with regional or final competition.

\subsection{Grading Systems}

Being able to automatically grade the programs produced by the contestants is very important for a good NOI. In some countries, produced code is inspected and graded manually by a jury, either with a precise grading scheme, or with a less systematic grading consisting of the attribution of a numerical score to the proposed solutions (Pohl, 2007).

Most countries have developed their own automatic grading systems able to safely execute code and to run them against test sets in order to establish a scored ranking (Chávez et al., 2014; Kostadinov et al., 2010; Maggiolo et al., 2014; Mareš and Blackham, 2012; Zhao et al., 2013).

Many countries adopted Contest Management System to organise their contests, a distributed system for running and organising a programming contest (CMS, 2015; Maggiolo et al., 2014). The main concerns of such graders are flexibility, efficiency, safety and security, independence to the programming language, and accuracy in execution time measurements. More general grading systems whose main goal is to be

Table 1

Participation to the different stages of the NOI for several countries

\begin{tabular}{llrrrc}
\hline Country & Rounds & School/Internet & Regional & Final & Selection \\
\hline BE & 3 & - & $\sim 150$ & $\sim 40$ & $\sim 15$ \\
BR & 2 & $\sim 8,000$ & - & & \\
CN & 4 & $\sim 80,000$ & $\sim 12,000$ & $?$ & $?$ \\
FI & 3 & $\sim 4,000$ & $\sim 200$ & $\sim 20$ & - \\
IN & 3 & - & $\sim 8,000$ & $\sim 300$ & $\sim 25$ \\
JP & 2 & $\sim 250$ & - & $\sim 50$ & $\sim 15$ \\
MX & 3 & $\sim 15,000$ & $\sim 2,000$ & $\sim 100$ & - \\
RO & 3 & $?$ & $?$ & $\sim 400$ & - \\
RS & 5 & $\sim 350$ & $\sim 150$ & $\sim 75$ & $?$ \\
SK & $2-3$ & $\sim 150$ & $?$ & $\sim 30$ & $\sim 10$ \\
TH & & & & $\sim 100$ & - \\
\hline
\end{tabular}


embedded in learning platforms that can be used to train pupils have also been produced more recently (Combéfis and le Clément de Saint-Marcq, 2012; Urbančič and Trampuš, 2012).

\subsection{Scoring and Selection of the IOI Delegation}

Most countries do have a simple way to select the four pupils to form the national delegation for the IOI, just selecting the four candidates having obtained the largest scores during the final round of the national Olympiad. In some countries, as in Macedonia, the sum of all the scores obtained at each stage of the national Olympiad is used to select the IOI delegation (Janceski and Pacovski, 2007).

In China or in Germany, candidates have the opportunity to defend themselves during an oral defence in front of a jury, as part of the selection process (Wang et al., 2007; Pohl, 2007). This additional interview is a great opportunity to check the English proficiency level of the candidates, for example. Other criteria such as the previous year medallist at the national Olympiad, at regional Olympiads and at the IOI are taken into account in the selection process, for example in Latvia (Opmanis, 2013).

Finally, in some countries, an additional contest, whose style is the same as the one of the IOI, is organised for the contestants that got the best scores during the NOI, in order to select the four contestants that will represent the country at the IOI. Usually, that final contest takes place after a training camp lasting several days that allows pupils to learn advanced algorithms and sharpen their programming skills.

\section{Trainings and Additional Activities}

Training contestants at various steps of the NOI is important since informatics is not present in school curricula of most countries. The most widespread activity is training camps, but countries are also organising other kinds of activities more specifically, to promote informatics or to foster cooperation between countries. For example, centres of excellence have been deployed in Romania, developing trainings for six disciplines, one of which is informatics (Cerchez and Andreica, 2008).

\subsection{Training Camps}

Trainings camps are organised by many countries. These camps last from a few days to weeks and are mainly organised at different moments in the selection process. They are mainly organised once the national IOI delegation has been selected, to train them for the IOI. But there are also training camps organised before the NOI final, or camps dedicated to the best contestants from the NOI, to help in the selection of the national IOI delegation, such as in Japan (Tani and Moriya, 2008). 
Some countries prepare their contestants for the IOI during several years, starting with the basics of programming, and then going to more advanced concepts in algorithmic methods. In addition to those more theoretical concepts, contestants are also training their code-writing skills. Trainings camps are mainly organised by teachers, but most countries also integrate former IOI contestants as tutors (Tani and Moriya, 2008). Usually, training camps are especially dedicated to train the contestants participating in NOI, or those selected for the IOI. Countries are starting to organise camps whose purpose is simply to spread informatics, providing introductory courses in computer science (Anido and Menderico, 2007).

In addition to those on-site supervised training camps, some countries encourage their contestants to take part in online contests organised by other countries or organisations, such as USACO, Chinese ACM-ICPC Online Judge, and Google Code Jam, for example. It is clear that using tasks from past IOIs is possible. Using those resources available online is a cheap way to propose trainings when lacking of human resources to supervise them (Combéfis and Wautelet, 2014). Correspondence camps, organised in Japan and in Slovakia, are a solution to do this supervision (Forišek, 2007; Tani and Moriya, 2008). It is clearly a good way to tackle the lack of qualified informatics teachers, that are only located in a few cities in most countries.

\subsection{Regional Olympiads and Cooperation}

Finally, in addition to the IOI, there exist other regional Olympiads, such as the Balkan Olympiad in Informatics (BOI), the Baltic Olympiad in Informatics (BOI), the CentralEuropean Olympiad in Informatics (CEOI) and the French-Australian Regional Informatics Olympiad (FARIO), for example.

Allowing the best pupils of the national Olympiads to participate at those regional Olympiads is a good training as highlighted by several countries. Of course, money has to be found to cover the participation expenses, except for online contests such as FARIO, for example.

Generally speaking, more cooperation between countries should be put in place, since the goals of every country regarding informatics and education are mainly the same. As it is the case with Slovakia, countries could be collaborating to prepare problems and help for their NIO and to prepare training camps (Forišek, 2007).

\subsection{Promotion Purpose}

As previously stated, national Olympiads are often also used as a tool for promoting informatics in schools. Some countries have introduced innovations in the national contest to help this promotion purpose.

Latvia introduced a special "first subtask" for every task of the country competition that can be solved by hand without the need of finding and implementing an algorithm to 
solve them (Opmanis, 2013). The main reason is to avoid the so-called " 0 -frustration" of contestants who understood the idea of the task, but were not able to write the algorithm to solve it. In Japan, four of the tasks of the first round are relatively simple, for the same reason (Tani and Moriya, 2008).

As highlighted in (Isal et al., 2014), establishing clear roles for the stakeholders involved in the NOIs for the promotion purpose is very important. The authors propose four levels of stakeholders starting with the participants and alumni contestants followed by universities and government. Each of these layers has to advertise the NOI since they can have different impacts and reach different publics.

\section{Conclusion}

To conclude this paper, IOI and related activities lead by participating countries are useful for promoting informatics in schools. Nevertheless, Olympiads need supplemental activities that must be organised to reach the informatics promotion goal that is promoting computer science and fostering its presence in education.

An observation that is made in several countries is that members of the national IOI delegation can often attend only one IOI since they are too aged. Two main reasons explain that observation: informatics is not in the curriculum of primary (8-12 years old) and secondary schools (12-18 years old), and selection processes sometimes last two years. One possible solution is to start the competition earlier and organising mini and junior Olympiads, such as the Junior Balkan Olympiad in Informatics, or to propose promotion activities such as the junior summer camps organised in New Zealand (Phillipps, 2010). Australia also went into this direction with their Australian Informatics Competition (AIC) which is an entry-level pen-and-paper competition targeted to youngers (Clark and Clapper, 2014). Collaborating with other contests targeted to younger pupils, such as the Bebras contest (Futschek and Dagiene, 2009), can also help to attract more people to join NOIs and IOIs.

Another big issue raised by most countries is the lack of materials that can be used by schools' teachers and for the trainings of contestants (Ilić and Ilić, 2012). Some countries are doing the tasks that are used in NOIs publicly available. Solutions as well as explanations of the solutions must also be available for such material to be useful and exploitable.

This review highlights that most countries share common ideas in the organisation of their NOI. Having a local competition level, that is not necessarily mandatory, is useful for promoting informatics among pupils and teachers. The second important activities are training camps. Two kinds of camps are organised: interleaved camps during the NOI that teach pupils algorithms and programming and selection camps with the best contestants from NOI to choose the national IOI delegation. Both camps are very important and should be organised if possible.

Finally, maintaining alumni contestants involved in the organisation of NOIs is also a good solution to help promote. Alumni associations can be found as it has been done in Indonesia (Isal et al, 2014). 
To conclude, five recommendations can be highlighted:

1. Promotion of informatics should start earlier, with initiatives and contests dedicated to younger pupils.

2. Collaboration and links with existing informatics contests, not necessarily related to programming, should be made.

3. Learning materials should be produced for teachers and trainers, to be used with their pupils and trainees.

4. Training camps and entry-level contests should be organised.

5. Relations with alumni contestants should be maintained to keep them involved in NOIs.

To work on those recommendations, more cooperation and collaboration should be established between countries, so they may get closer at reaching the common goal of spreading computer science and improving its presence in education.

\section{References}

Anido, R., Menderico, R. (2007). Brazilian olympiad in informatics. Olympiads in Informatics, 1, 5-14.

Casadei, G., Fadini, B., De Vita, M.G. (2007). Italian olympiads in informatics. Olympiads in Informatics, 1, 24-30.

Cepeda, A., Garcia, M. (2011). Mexican olympiad in informatics. Olympiads in Informatics, 5, 128-130.

Cerchez, E., Andreica, M. (2008). Romanian national olympiads in informatics and training. Olympiad in Informatics, 2, 37-47.

Chávez, L., González, A., Ponce, J. (2014). omegaUp: cloud-based contest management system and training platform in the Mexican olympiad in informatics, Olympiads in Informatics, 8, 169-178.

Choijoovanchig, L., Uyanga, S., Dashnyam, M. (2007). The informatics olympiad in Mongolia. Olympiads in Informatics, 1, 31-36.

Clark, D., Clapper, M. (2014). The Australian informatics competition. Olympiads in Informatics, 8, $179-189$.

CMS (2015). Contest Management System. https : / / cms . readthedocs . org/en/v1 . 2 /

Combéfis, S., Leroy, D. (2011). Belgian olympiads in informatics: the story of launching a national contest. Olympiads in Informatics, 5, 131-139.

Combéfis, S., le Clément de Saint-Marcq, V. (2012). Teaching programming and algorithm design with pythia, a web-based learning platform. Olympiads in Informatics, 6, 31-43.

Combéfis, S., Wautelet, J. (2014). Programming trainings and informatics teaching through online contest. Olympiads in Informatics, 8, 21-34.

Forišek, M. (2007). Slovak IOI 2007 Team selection and preparation. Olympiads in Informatics, 1, 57-65.

Forišek, M. (2013). Pushing the boundary of programming contests. Olympiads in Informatics, 7, $23-35$.

Futschek, G., Dagiene, V. (2009). A contest on informatics and computer fluency attracts school students to learn basic technology concepts. In: Proceedings of the 9th World Conference on Computers in Education.

Ilić, A., Ilić, A. (2012). IOI Trainings and Serbian competitions in informatics. Olympiad in Informatics, 6 , 158-169.

Isal, Y.K., Liem, M.M.I., Mulyanto, A., Marshal, B. (2014). Indonesian olympiad in informatics: significant advancements between 2010 and 2014. Olympiads in Informatics, 8, 191-198.

Janceski, M., Pacovski, V. (2007). Olympiads in informatics: Macedonian experience, needs, challenges. Olympiads in Informatics, 1, 66-78.

Kaykobad, M. (2013). Bangladesh olympiads in informatics. Olympiads in Informatics, 7, 163-167.

Koivisto, J. (2011). The national computer olympiads and the IOI participation in Finland. Olympiads in Informatics, 5, 147-149.

Kostadinov, B., Jovanov, M., Stankov, E. (2010). A new design of a system for contest management and grading in informatics competitions. In: Web Proceedings of ICT Innovations 2010. 87-96. 
Maggiolo, S., Mascellani, G., Wehrstedt, L. (2014). CMS: a growing grading system. Olympiads in Informatics, $8,123-131$.

Mandaria, G. (2013). Olympiads in informatics: the Georgian experience. Olympiads in Informatics, 7, 168 174.

Malaivongs, K. (2011). Preparing students for IOI: Thailand country report. Olympiads in Informatics, 5, 150154.

Manev, K., Kelevedjiev, E., Kapralov, S. (2007). Programming contests for school students in Bulgaria. Olympiads in Informatics, 1, 112-123.

Mareš, M., Blackham, B. (2012). A new contest sandbox. Olympiads in Informatics, 6, 100-109.

Mukund, M. (2013). The Indian computing olympiad. Olympiad in Informatics, 7, 175-179.

Opmanis, M. (2013). Latvian olympiad in informatics - lessons learned. Olympiads in Informatics. 7, 78-89.

Phillipps, M. (2010). The New Zealand experience of finding informatics talent. Olympiads in Informatics, 4, $104-112$.

Pohl, W. (2007). Computer science contests in Germany. Olympiads in Informatics, 1, 141-148.

Tani, S., Moriya, E. (2008). Japanese olympiad in informatics. Olympiads in Informatics, 2, 163-170.

Urbančič, J, Trampuš, M. (2012). Putka - a web application in support of computer programming education. Olympiads in Informatics, 6, 205-211.

Verhoeff, T. (1997). The role of competitions in education. In: Proceedings of the Future World Educating for the 21 st Century Conference and Exhibition.

Wang, H., Yin, B., Li, W. (2007). Development and exploration of Chinese national olympiad in informatics (CNOI). Olympiads in Informatics, 1, 165-174.

Wang, H., Yin, B., Liu, R., Tang, W., Hu, W. (2010). Selection mechanism and task creation of Chinese national olympiad in informatics. Olympiads in Informatics, 4, 142-150.

Zhao, Q., Wang, F., Yin, B., Sun, H. (2013). Arbitrer: the evaluation tool in the contests of the China NOI. Olympiads in Informatics, 7, 180-185.

Zrimec, M. (1989). The report of Slovenian association of technical culture organisation. In: Proceedings of the International Congress on Education and Informatics: Strengthening International Cooperation. ED.89/ $\mathrm{WS} / 62$.

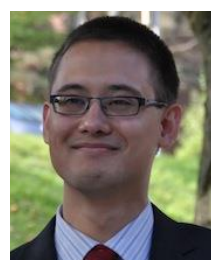

Dr. S. Combéfis obtained his PhD in engineering in November 2013 from the Université catholique de Louvain in Belgium. He is currently working as a lecturer at the École Centrale des Arts et Métiers (ECAM), where he is mainly teaching informatics. He also got an advanced master in pedagogy in higher education in June 2014. He founded the Belgian Olympiad in Informatics (be-OI) with Damien Leroy in 2010. In 2012, he introduced the Bebras contest in Belgium and at the same time he founded the CSITEd non-profit organisation that aims at promoting computer science in secondary schools.

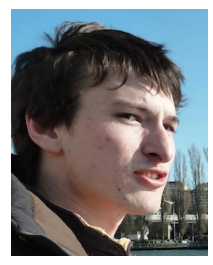

A. Paques is studying electronics engineering at École Centrale des Arts et Métiers (ECAM), in Brussels. He is now a first year master student. In addition to his passion for engineering, he likes programming. $\mathrm{He}$ has also been involved in the Bebras final in 2015, where he taught informatics to secondary school students. Since then, he has started to contribute to several projects related to informatics teaching for pupils. 